COLON

\title{
The $C d \times 2$ homeobox gene has a tumour suppressor function in the distal colon in addition to a homeotic role during gut development
}

\author{
C Bonhomme, I Duluc, E Martin, K Chawengsaksophak, M-P Chenard, M Kedinger, F Beck, \\ J-N Freund, C Domon-Dell
}

Gut 2003;52:1465-1471

See end of article for authors' affiliations

\section{Correspondence to:}

J-N Freund, INSERM Unit

381, 3 Ave Molière,

67200 Strasbourg,

France;

jean-noel.freund@

inserm.u-strasbg.fr

Accepted for publication 28 May 2003
Background: During development, the homeobox gene $C d x 2$ exerts a homeotic function, providing the positional information necessary for correct specification of the midgut endoderm. This is illustrated by the non-neoplastic gastric-type heteroplasias present at birth in the pericaecal region of $C d x 2^{+/-}$mice. Furthermore, intestinal expression of $C d \times 2$ continues throughout life but diminishes in colorectal cancers compared with adjacent normal tissue, suggesting a role in tumorigenesis.

Aim: To investigate the consequence of altered $C d x 2$ expression on colon tumour initiation and/or progression.

Methods: Heterozygous $\mathrm{Cd} \times 2^{+/-}$mice were analysed for spontaneous malignant tumours and for tumour development after treatment with a DNA mutagen, azoxymethane.

Results: $C d \times 2^{+/-}$mice did not spontaneously develop malignant tumours. After azoxymethane treatment, the gastric-like heteroplasias in the pericaecal region did not evolve into cancer indicating that they are not precancerous lesions. However, azoxymethane treated $C d x 2^{+/-}$mice developed tumours specifically in the distal colon 12 weeks after azoxymethane treatment whereas no tumours were found in wild-type littermates at this stage. Histopathological and molecular analyses indicated that these tumours were invasive adenocarcinomas that recapitulated the malignant sequence observed in the majority of sporadic colorectal cancers in human. In addition, we found that the colonic epithelium was less sensitive to radiation induced apoptosis in $\mathrm{Cd} \times 2^{+/-}$than in wild-type mice.

Conclusion: This study provides the first experimental evidence that $C d \times 2$ is a tumour suppressor gene involved in cancer progression in the distal colon. This action in adults is functionally and geographically distinct from its homeotic role during gut development.
$\mathrm{H}$ omeobox genes encode transcription factors that play crucial roles in early developmental processes including patterning and cell identity. Some are expressed in adulthood and alterations are linked to malformations, metabolic diseases, and cancers. ${ }^{1}$ In cancer, homeobox genes generally act as proto-oncogenes ${ }^{2}$ while a tumour suppressor function has recently been attributed to one of them in the prostate. $^{3}$ Colorectal cancer is the second most important cancer in Western countries as regards incidence and mortality. Colorectal cancers are associated with the stepwise accumulation of genetic alterations involving many tumour suppressor genes and proto-oncogenes such as APC, K-ras, p53, and Bcl2. ${ }^{4}$ These genes are also relevant for cancers outside the gut and no intestine specific gene has so far been implicated in colorectal cancer.

The Cdx2 homeobox gene, homologous to the Drosophila gene caudal, has an essential role during early development. Indeed, in mice, $C d \times 2$ deficiency in $C d \times 2^{-1-}$ animals causes embryonic lethality in the peri-implantation period. ${ }^{6}$ Embryonic expression begins at 8.5 days post coitum in the three germ layers. Later, its expression is restricted to the intestinal endoderm in fetuses and is retained throughout adulthood in the intestinal epithelium. Maximal expression occurs in the pericaecal region and proximal colon, with a decline towards the distal end of the colon. ${ }^{7-9}$ Besides early lethality in homozygous knockouts, heterozygous $C d x 2^{+/-}$ mice have an intestinal phenotype characterised by morphological lesions in the pericaecal region and proximal colon. Although initially suggested to be neoplastic, ${ }^{6}$ thorough analysis revealed that these are non-cancerous lesions present at birth, comprising hyperplastic but not dysplastic areas and exhibiting morphological and molecular features characteristic of gastric mucosa. ${ }^{10}$ Thus these lesions are gastric-like heteroplasias that represent a homeotic reversion of the developing gut endoderm to the "default" phenotype of the stomach. ${ }^{11}{ }^{11}$ Conversely, ectopic expression of $C d x 2$ in the stomach causes transdifferentiation towards the intestinal phenotype. ${ }^{12} 13$ Together, these data demonstrate that $C d \times 2$ has a crucial homeotic function during the development of the gastrointestinal tract, specifying midgut as opposed to foregut endoderm.

Unlike this critical role during gut morphogenesis, the function of $C d \times 2$ remains elusive in the adult intestine. Strikingly, expression of $C d x 2$ decreases in human colorectal cancers in relation to the tumour grade and it is lost in minimally differentiated colon carcinomas. ${ }^{14} 15$ In addition, the gene is downregulated by oncogenic pathways in colon cancer cells. ${ }^{16}{ }^{17}$ These observations led us to hypothesise that $C d \times 2$ has a tumour suppressor function. However, no experimental evidence for this property has been provided to date. Instead, the low frequency of genetic alterations found at the $C d \times 2$ locus in human colorectal cancers suggests a minor role for $C d x 2$ in carcinogenesis. ${ }^{18}$ In this study, we have addressed the role of $C d \times 2$ in colon tumour initiation and/or progression using $C d x 2^{+/-}$mice.

Abbreviations: $A O M$, azoxymethane; RT-PCR, reverse transcriptasepolymerase chain reaction. 


\section{MATERIALS AND METHODS \\ Mice and treatments}

Heterozygous $\mathrm{Cd} \times 2^{+/-}$mice in a mixed 129Sv/C57BL6 background ${ }^{6}$ were housed under standard laboratory conditions. Two month old heterozygotes and their wild-type littermates were injected intraperitoneally with $10 \mathrm{mg} / \mathrm{kg}$ azoxymethane (AOM; Sigma, St Louis, Missouri, USA) in $150 \mathrm{mM} \mathrm{NaCl}$ once a week for five weeks. Mice were observed weekly for morbidity and killed by cervical disruption either two weeks after the last injection for short term studies or 12 or 29 weeks after the last injection for long term studies. The colons were removed, flushed with ice cold phosphate saline buffer, and opened longitudinally. For short term studies, distal colons fixed in $4 \%$ paraformaldehyde were stained with $0.2 \%$ methylene blue and aberrant crypt foci were scored blindly under the microscope by two independent observers. For long term studies, the number, size, and location of the tumours detected macroscopically were determined. Tumours and adjacent tissues as well as gastric-like heteroplasias were fixed in $4 \%$ paraformaldehyde and paraffin embedded, snap frozen for DNA and RNA analysis, or embedded in Tissue Tek II (Sakura Finetek, Torrance, California, USA). Another group of heterozygotes and their wild-type littermates were whole body irradiated ( 8 Gy) using a Cobalt 60 source and sacrificed four hours later. The colons were fixed in paraformaldehyde and embedded in paraffin.

\section{Immunohistochemistry}

Paraffin embedded sections $(5 \mu \mathrm{m})$ were deparaffinised and heated for 10 minutes in $10 \mathrm{mM}$ citrate buffer $(\mathrm{pH}$ 6.2) for antigen retrieval. Immunohistochemical staining used the Vectastain ABC kit (Vector Laboratories Inc, Burlingame, USA) with the primary antibodies raised against Ki67 (dilution 1:50, ab833; Abcam, Cambridge, UK), $\beta$-catenin (dilution 1:150, 7D8; Upstate Biotechnology, Lake Placid, New York, USA), activated caspase-3 (dilution 1:1500, AF835; R\&D System, Wiesbaden, Germany), Cdx2 (dilution 1:100, 392M; Biogenex, San Ramon, California, USA), and Cdxl. The rabbit polyclonal anti-Cdxl antibody, CIC, was raised against the peptide CPTNAGLLGTPSPVPVKEEFLP corresponding to the $\mathrm{C}$ terminal part of murine $\mathrm{Cdxl}$ (Eurogentec, Serairy, Belgium) and purified by immunoaffinity using the peptide coupled to a Sulfo-link column (Pearce, Rockford, Illinois, USA). Biotinylated antimouse or antirabbit secondary antibodies (Vector Laboratories Inc., Burlingame, California, USA) were used at a 1:200 dilution.

\section{RT-PCR and genomic DNA analyses}

RNA was extracted from heteroplasias, colon tumours, and adjacent normal tissue using Tri-Reagent (MRC, Cincinnati, Ohio, USA); $1 \mu \mathrm{g}$ was used for semiquantitative reverse transcriptase-polymerase chain reaction (RT-PCR), as previously described, ${ }^{16}$ with primers to detect the $C d x 1, C d x 2$, and $C d x 4$ transcripts, and normalisation with cytokeratin 19 mRNA (table 1).

Tumour cryosections were used to separately microdissect carcinomatous areas and normal adjacent colon epithelium using a laser dissection microscope (Pixcell II; Arcturus Engineering, Mountain View, California, USA). Genomic DNA was extracted as recommended by the supplier. PCR amplification of the genomic fragments encompassing the three exons of the $C d x 2$ gene was carried out for 40 cycles $\left(94^{\circ}\right.$ for 30 seconds, $58^{\circ} \mathrm{C}$ for 30 seconds, and $72^{\circ} \mathrm{C}$ for two minutes) using the primers listed in table $\mathrm{l}$ and the Expand $20 \mathrm{~kb}$ Plus System (Roche, Mannheim, Germany). PCR fragments were run on 3\% agarose gels, purified with the Qiaquick PCR purification kit (Qiagen, Courtaboeuf, France), and sequenced.

\section{RESULTS}

Reduced expression of $C d \times 2$ in $C d \times 2^{+/-}$mice has no effect on tumour initiation

To determine if reduced expression of $C d x 2$ triggers spontaneous cancerous initiation in the gut, heterozygous $C d x 2^{+/-}$ mice were followed over several generations. As previously described, ${ }^{6}{ }^{10}$ gut histology in these mice confirmed the presence of organotypic gastric-like heteroplasias in the pericaecal region and proximal colon while no such lesions were present in wild-type littermates. Apart from these homeotic lesions, heterozygous animals did not spontaneously develop any cancerous lesion in the gut, thus confirming previous observations. ${ }^{10}{ }^{11}$ Based on the two hits model of cancer, we next compared heterozygous mice and wild-type littermates for their sensitivity to a DNA mutagen, $\mathrm{AOM}$, injected intraperitoneally for five weeks. In the first series of experiments, mice were killed two weeks after the last injection and the distal half of the colon was analysed for aberrant crypt foci, thought to represent a primary step in tumorigenesis. After this short term delay, aberrant crypt foci occurred in the colon of all AOM treated mice irrespective of the genotype, while none was detected in untreated animals. However, the number of foci did not differ significantly between $C d x 2^{+/-}(8.8(4.3), \mathrm{n}=8)$ and wild-type mice (7.2 $(4.8), \mathrm{n}=8)$. Together, these results indicate that reduced expression of $C d x 2$ in heterozygous $C d x 2^{+/-}$mice has no effect on initiation of intestinal tumours.

\section{Gastric-like heteroplasias do not evolve into cancer after long term AOM treatment}

We set out to determine if long term treatment with the DNA mutagen triggers cancerous evolution of the gastric-like heteroplasias arising spontaneously in the pericaecal region and proximal colon of $C d x 2^{+/-}$mice. To this end, $C d x 2^{+/-}$mice and wild-type littermates ( 11 each) were treated with AOM for five weeks and killed 12 weeks later. During the week after the first injection, two $C d x 2^{+/-}$mice and two wild-type animals died. Twelve weeks after the last AOM injection, histopathological examination failed to reveal any malignant transformation of the gastric-type heteroplasias present in $C d x 2^{+/-}$mice (fig 1A). Within the heteroplasias of AOM treated $C d x 2^{+/-}$mice, the pattern of cell proliferation labelled by anti-Ki67 antibody was unchanged compared with untreated heterozygotes (not shown), and $\beta$-catenin labelling exclusively stained the cell membranes (fig lB). We conclude from these results that the gastric-like heteroplasias that arise as homeotic lesions in the pericaecal and proximal colon mucosa during gut development do not undergo malignant evolution after treatment with a DNA mutagen.

We analysed expression of the three $C d x$ paralogues, $C d x l$, $C d x 2$, and $C d x 4$, in gastric-like heteroplasias. $C d x 2$ and $C d x 1$ are normally present in the adult intestinal epithelium whereas $C d x 4$ is restricted to the embryonic period. In accordance with previous data, ${ }^{10}$ RT-PCR and immunohistochemistry showed that $C d \times 2$ mRNA and protein were absent in the heterotoplasias of $C d x 2^{+/-}$mice, and the same was observed in heterozygous animals 12 weeks after AOM treatment (fig IC, E). We also found that, in common with $C d x 2, C d x 1$ expression was absent in heteroplasias of both untreated and treated mice (fig 1D, E) which fits with the fact that this homeobox gene is not expressed in the normal stomach. No $C d x 4$ mRNA was found in heteroplasias (data not shown).

\section{Heterozygous $C d \times 2^{+/-}$mice are hypersensitive to AOM induced colon cancers}

Next, we looked for the presence of intestinal lesions, distinct from gastric-like heteroplasia, 12 weeks after AOM treatment in $C d x 2^{+-}$mice, which we compared with wild-type 


\begin{tabular}{|c|c|c|c|}
\hline Gene & Primer sequence & $\begin{array}{l}\text { Size of PCR } \\
\text { fragment (bp) }\end{array}$ & No of cycles \\
\hline$C d \times 1$ & $\begin{array}{l}\text { 5'-GCGCAGAGGCCGACGCCCTACGAGT-3' } \\
\text { 5'-TGTCACTTGCTCCTGCCCG-3' }\end{array}$ & 250 & $22-26$ \\
\hline$C d \times 2$ & $\begin{array}{l}\text { 5'-AAAGTGAGCTGGCTGCCACACTTG-3' } \\
\text { 5'-TCCATCAGTAGATGCTGICGTGG-3' }\end{array}$ & 426 & $22-26$ \\
\hline$C d \times 4$ & $\begin{array}{l}\text { 5'-TCCCAGCAGGAGCCGTCACAGCCCCTA-3' } \\
5^{\prime} \text {-CTGATGGAGCCAGAGTCACTITGCAC-3' }\end{array}$ & 317 & 40 \\
\hline CK19 & $\begin{array}{l}\text { 5'-TGAGATTGAGCTGCAGTCCCAGCT-3' } \\
5^{\prime} \text {-TCCCAGGGGAGTCTCGCTGGTAGC-3' }\end{array}$ & 312 & $18-22$ \\
\hline$C d \times 2 /$ exon 1 & $\begin{array}{l}\text { 5'-ACAGCATGGTGAGGTCTGCT-3' } \\
\text { 5'-TGTCCTGGCTAGGAGCTGGCAGACA-3' }\end{array}$ & 823 & 40 \\
\hline$C d \times 2 /$ exon 2 & $\begin{array}{l}\text { 5'-TCCATCAGTGGATGGAGAGAAATGA-3' } \\
5^{\prime} \text {-TAATGCTACCCATAAGATGC-3' }\end{array}$ & 489 & 40 \\
\hline$C d \times 2 /$ exon 3 & $\begin{array}{l}\text { 5'-GCTTGGGGAACATTTCCCAAACTCAGTG-3' } \\
5^{\prime} \text {-TCTCGCAGCGTCCATACTCCTCAT-3' }\end{array}$ & 361 & 40 \\
\hline
\end{tabular}

littermates also treated with the DNA mutagen. In the distal half of the colon, and completely separated geographically from gastric-like heteroplasia, polyp-like tumours were found in all $C d x 2^{+/-}$mice 12 weeks after AOM treatment $(n=9)$ (fig 2A). Strikingly, no tumours occurred in any of the wildtype animals at this stage after AOM treatment $(n=9)$. In both wild-type and $C d \times 2^{+--}$mice, the proximal colon and small intestine remained tumour free. Three to 11 tumours arose per $C d \times 2^{+/-}$animal with a mean value of 7.66, and a total of 69 tumours in nine AOM treated $C d x 2^{+/-}$mice. Tumour masses were 1-4 $\mathrm{mm}$ in diameter. Histopathological analysis revealed that they were typical adenocarcinomas comprising areas with tubular structures lined by a single polarised epithelium (subsequently referred to as adenomatous regions), and highly disorganised areas containing pleomorphic nuclear profiles characteristic of carcinomatous regions (fig 2B, D, E). Occasionally, groups of cells penetrated the muscularis mucosa and infiltrated the submucosa, indicating invasive properties (fig 2C). Ki67 immunolabelling revealed active cell proliferation in both adenomatous and carcinomatous regions (fig 2F, G). $\beta$ Catenin was associated with cell membranes in the adenomatous regions but shifted to the cytoplasm and the nucleus in carcinomatous regions (fig $2 \mathrm{H}, \mathrm{I}$ ).

An additional group of three wild-type animals was kept for 29 weeks instead of 12 weeks after AOM treatment to determine if this longer delay allows tumour appearance in wild-type animals, as reported in the literature. Two of
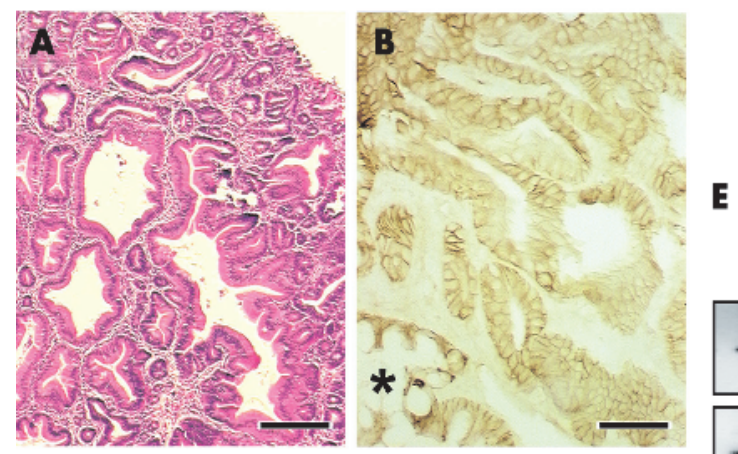

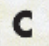

C

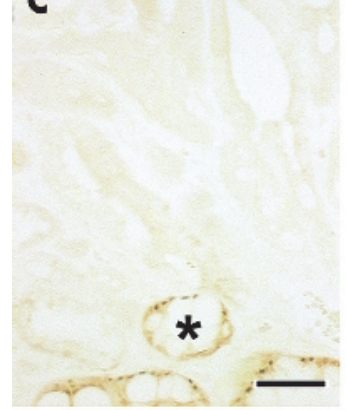

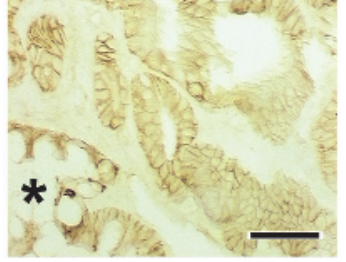

D

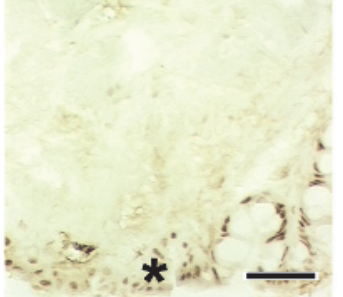

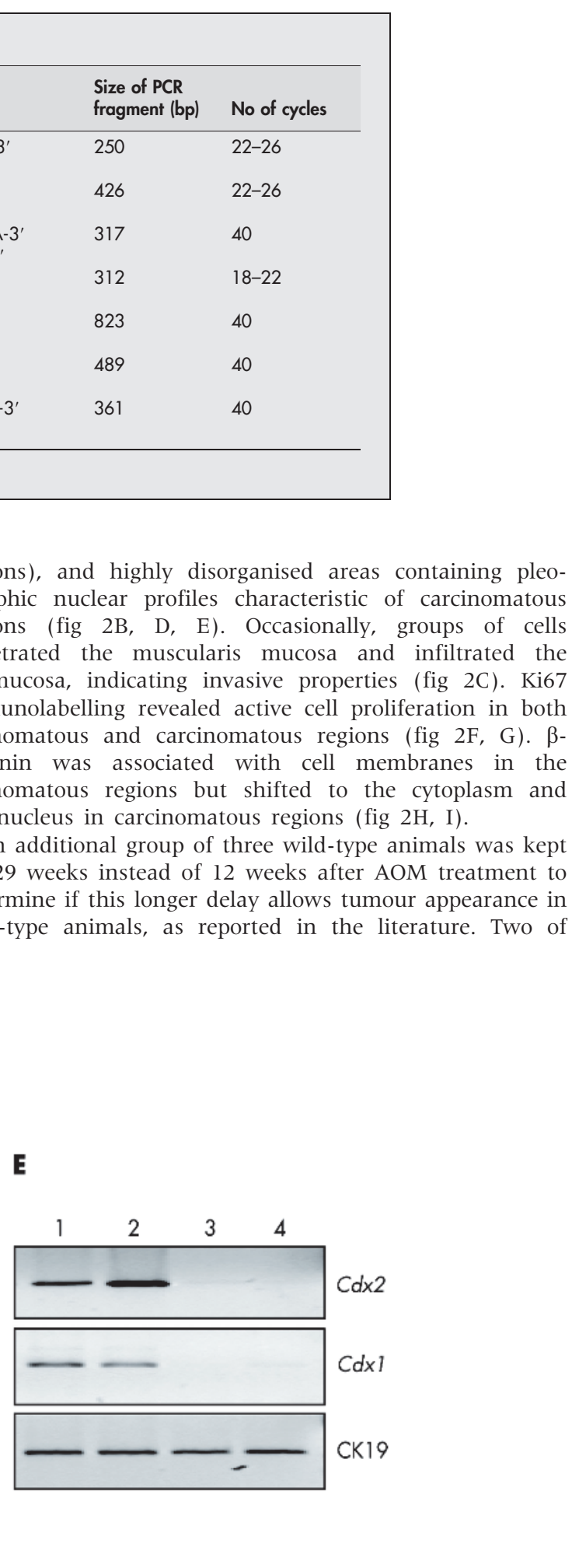

E

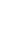

\section{(1)}




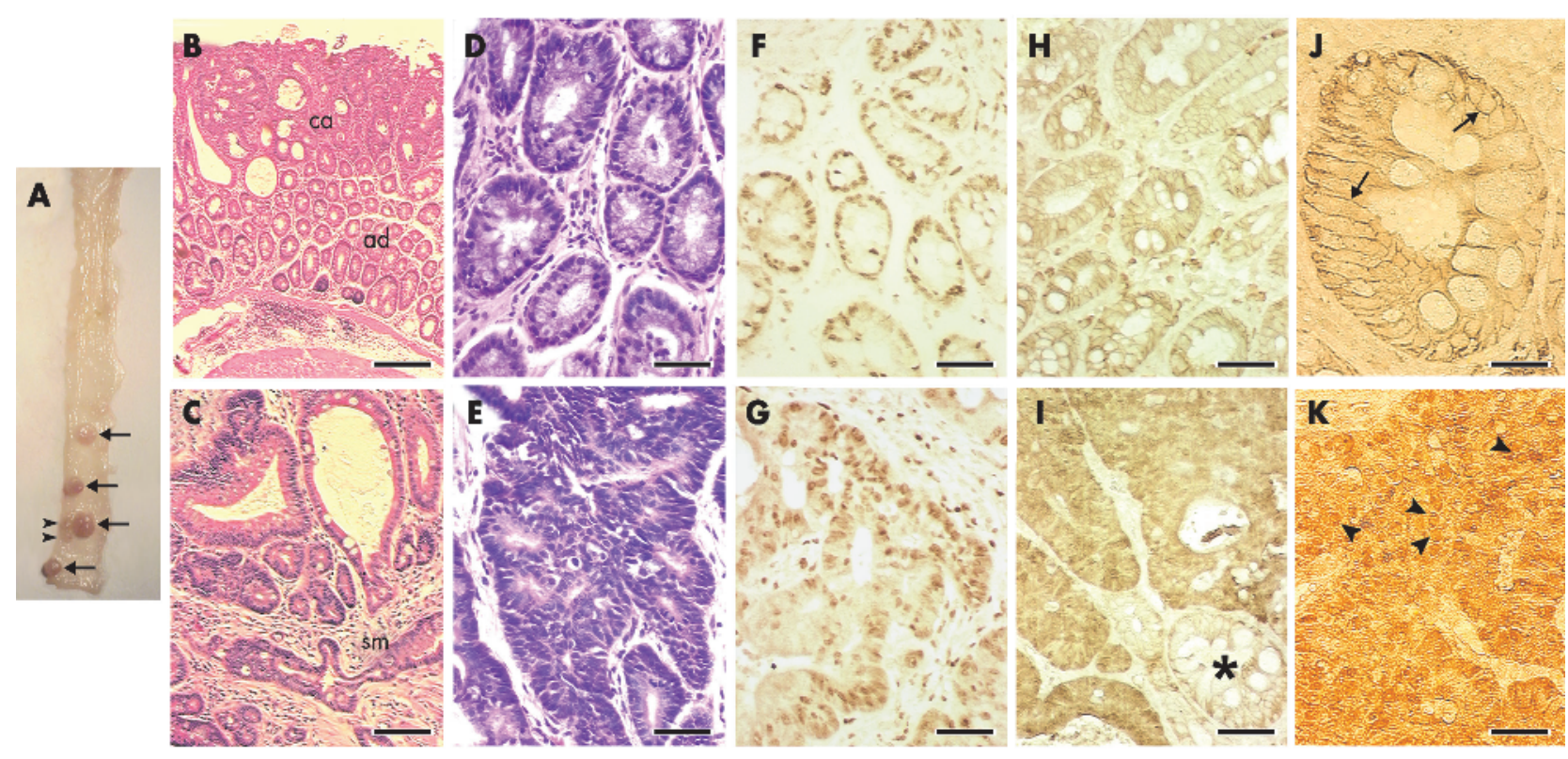

Figure 2 Adenocarcinomas in the distal colon of azoxymethane (AOM) treated $\mathrm{Cdx} 2^{+/-}$mice. (A) Macroscopic view of the distal part of the colon (viewed anteroposteriorly from the upper part of the illustration) in a $\mathrm{Cdx} 2^{+/-}$mouse, 12 weeks after $\mathrm{AOM}$ treatment, showing two small (arrowheads) and four large (arrows) tumours. (B) Haematoxylin and eosin (H\&E) staining of a tumour with adenomatous (ad) and carcinomatous (ca) areas. (C) Epithelial structures infiltrate the submucosa (sm). Larger magnification of an adenomatous (D) and a carcinomatous (E) area. Immunolabelling of Ki67 reveals active cell proliferation in both adenomatous (F) and carcinomatous (G) areas. The cellular distribution of $\beta$-catenin is very different in the adenomatous $(\mathrm{H})$ and carcinomatous (I) areas. Indeed, in the adenomatous area (J), $\beta$-catenin is membranous (arrows) whereas in the carcinomatous area $(\mathrm{K})$ it accumulates within the whole cellular volume, including the nucleus (arrowheads). *Adenomatous gland with membranous $\beta$-catenin in the vicinity of the carcinomatous area. Bar is $200 \mu \mathrm{m}$ in (B, C), $50 \mu \mathrm{m}$ in (D-I), and $20 \mu \mathrm{m}$ in (J, K).

three animals showed one and five tumours, respectively, in the distal colon. Histopathologically, these tumours were adenocarcinomas, indistinguishable from those previously described in $\mathrm{Cd} 2^{+/-}$animals. High Ki67 labelling and a membranous to cytoplasmic/nuclear shift of $\beta$-catenin was also observed in adenomatous and carcinomatous areas (data not shown).

Together, these findings demonstrate that heterozygous $C d x 2^{+-}$mice are hypersensitive to DNA mutagen induced tumorigenesis in the distal colon compared with wild-type animals, and that the reduction in $C d x 2$ expression facilitates tumour progression.

\section{Status of $C d x$ genes in adenocarcinomas of the distal colon}

We analysed the pattern of $C d x$ gene expression in tumours of AOM treated $C d x 2^{+/-}$mice. This pattern was different from that shown above in heteroplasias present in the pericaecal region of the same animals. By RT-PCR (fig 3A), we demonstrated that $C d \times 2$ mRNA was reduced, although not absent, in tumours compared with the adjacent normal mucosa. Immunohistochemistry revealed few glands retaining a weak amount of $\mathrm{Cdx} 2$ protein in the adenomatous regions (fig $3 \mathrm{~B}$ ) and no staining in carcinomatous areas (fig 3C). These findings are in keeping with the decline in $C d \times 2$ expression with tumour grade in human colorectal carcinomas. ${ }^{14}$ Unlike $C d x 2, C d x 1$ mRNA was abundant in some regions of the tumours (fig 3A). Cdxl immunostaining was strong in the nuclei of the adenomatous glands whereas the protein was absent in carcinomatous regions (fig 3D E). No expression of $C d x 4$ mRNA was detected in the tumours. In wild-type mice, tumours that developed 29 weeks after AOM treatment showed a $C d \times 2$ pattern identical to that described above in tumours collected 12 weeks after AOM treatment in $C d \times 2^{+/-}$mice (not shown).
In human colon cancer, reduced expression of $C d x 2$ is infrequently associated with $C d \times 2$ gene loss or mutation. ${ }^{18}{ }^{19}$ This prompted us to determine the status of the single wild-type copy of the $C d x 2$ gene in tumours of AOM treated $C d \times 2^{+/-}$mice. To this end, genomic DNA was extracted by microdissection from cells of the carcinomatous regions in three distinct tumours and from the adjacent normal mucosae. Genomic DNAs were used as templates for PCR amplification of fragments encompassing the three exons of the $C d x 2$ gene. PCR products of expected sizes were obtained from genomic DNAs extracted from both normal mucosae and carcinomatous regions, indicating no loss of the single wild-type copy of the $C d x 2$ gene in tumours (fig 4A). Sequencing these PCR fragments failed to reveal any single nucleotide change in carcinomatous regions compared with normal mucosae. Together, these data indicate that the reduction in $\mathrm{Cdx} 2$ expression in tumours of AOM treated $C d \times 2^{+--}$mice is not a consequence of loss or mutation of the single wild-type $C d x 2$ allele.

\section{Reduced apoptosis in the colon epithelium of $C d \times 2^{+/-}$ mice}

In an attempt to address the hypersensitivity of $C d x 2^{+/-}$mice to cancer, we compared proliferation rates and response to an apoptotic stress in the colon of $C d \times 2^{+-}$and wild-type mice. Ki67 immunolabelling did not reveal any significant differences in cell proliferation between the two groups (results not shown). Next, sensitivity to apoptosis was compared in $C d x 2^{+/-}$mice and wild-type littermates subjected to $\gamma$ irradiation at a dose of 8 Grays. Apoptotic bodies concentrating in the crypt base of the distal colon were visualised four hours after irradiation using an antibody raised against activated caspase- $3^{20}$ (fig 4B). The mean number of caspase- 3 labelled apoptotic bodies per crypt in $\mathrm{Cdx}^{+/-}$animals was half that found in wild-type animals (fig 4C). These results indicate that the colon epithelium is more resistant to 
A
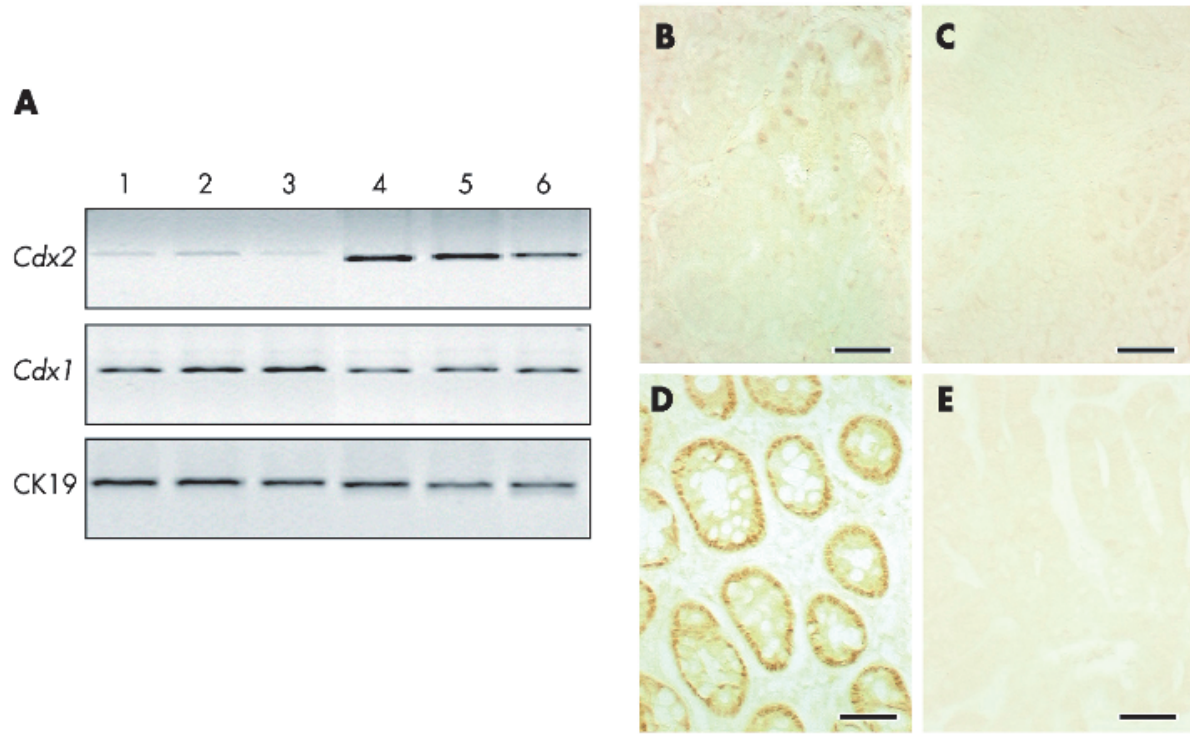

Figure $3 \mathrm{Cdx}$ gene expression in tumours of azoxymethane $(\mathrm{AOM})$ treated $\mathrm{Cdx} 2^{+/-}$mice. (A) Reverse transcriptase-polymerase chain reaction analysis of $C d \times 2$ and $C d \times 1$ mRNAs from three independent adenocarcinomas (lanes 1-3) and from the corresponding normal adjacent mucosa (lanes 4-6) in AOM treated $C d \times 2^{+/-}$mice. Normalisation was achieved with cytokeratin 19 (CK19) mRNA. (B) Immunostaining of Cdx2 protein reveals low and irregular immunoreactivity in a few glands of the adenomatous areas whereas $\mathrm{Cdx} 2$ expression is lost in carcinomatous areas (C). Epithelial cells in the adenomatous areas express a high amount of $C d x 1$ protein (D) whereas $C d x 1$ expression is essentially absent in carcinomatous areas (E). Bar is $50 \mu \mathrm{m}$ in (B-E).

$\gamma$ irradiation induced apoptosis in $C d x 2^{+/-}$than in wild-type mice.

\section{DISCUSSION}

The Cdx2 homeobox gene exerts a homeotic function during morphogenesis of the gastrointestinal tract, as assessed by the gastric-like heteroplasias resulting from local loss of $C d \times 2$ expression in the pericaecal region of $C d x 2^{+/-}$mice, ${ }^{610}{ }^{11}$ and by the intestine-like transdifferentiation of the gastric mucosa in transgenic mice expressing ectopically $C d x 2$ in the stomach. ${ }^{12}{ }^{13}$ The gastric-like heteroplasias are present at birth in the pericaecal region of $C d x 2^{+/-}$mice, they do not exhibit neoplastic foci, and they do not evolve into cancers, neither spontaneously nor after treatment with a DNA mutagen, AOM. Therefore, there is no experimental evidence to date to consider these heteroplasias as precancerous lesions. However, we have shown here that reduction of
$C d \times 2$ expression in $C d x 2^{+/-}$mice confers susceptibility to AOM induced carcinogenesis in the distal colon. Hence this study provides the first experimental evidence that $C d x 2$ is a colon tumour suppressor gene.

The fact that $C d x 2^{+/-}$mice do not spontaneously develop malignant tumours but are hypersensitive to chemically induced cancers indicates that the reduction in $C d \times 2$ expression facilitates tumour progression although there is no evidence for a role in tumour initiation. However, we cannot rule out from the present experiments that total loss of $C d x 2$ expression, as observed in minimally differentiated human colon carcinomas, ${ }^{15}$ is the initiating event in these types of cancer. Unlike tumour suppressor genes such as APC and p53, which act in the colon and also outside of the gut, ${ }^{45}$ $C d \times 2$ is the first intestine specific tumour suppressor. While homeobox genes are generally considered as proto-oncogenes, ${ }^{2}$ this study has demonstrated the tumour suppressor
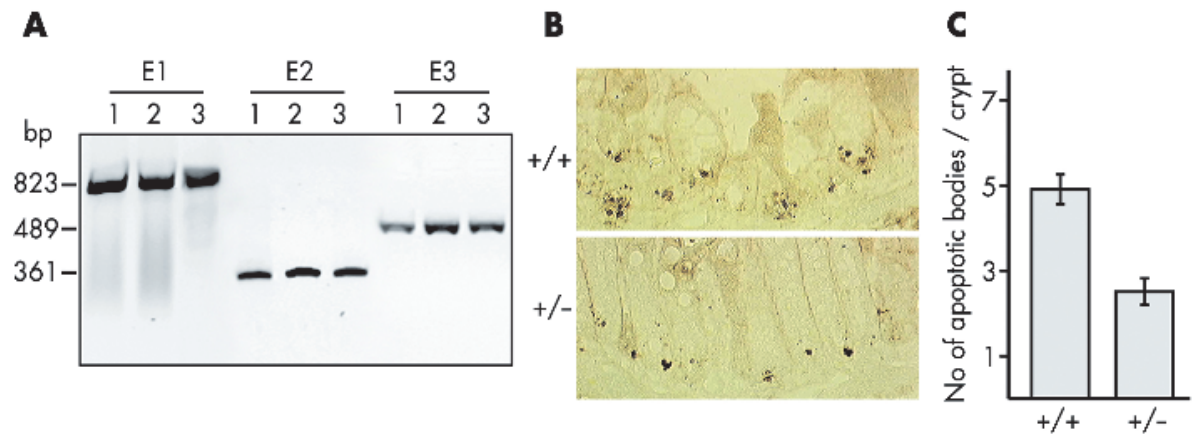

Figure 4 Lack of $C d \times 2$ gene deletion and reduced apoptosis in $C d \times 2^{+/-}$mice. (A) Genomic DNAs were extracted from laser microdissected normal colon epithelium (lane 1) and from carcinomatous areas of two independent tumours (lanes 2 and 3 ) in azoxymethane (AOM) treated Cdx2 $2^{+/-}$mice. Primer pairs specific for exon 1 (E1), exon 2 (E2), and exon 3 (E3) of the $C d \times 2$ gene efficiently generated polymerase chain reaction products from normal and tumour DNA samples. (B) Apoptotic bodies (brown dots) at the crypt base of $\gamma$ irradiated wild-type and $\mathrm{Cd} \times 2^{+/-}$mice were detected with anti-activated caspase-3. (C) Number of apoptotic bodies per colonic crypt in wild-type and $C d \times 2^{+/-}$mice after $\gamma$ irradiation $(n=50$ crypts, $\mathrm{p}<0.001)$. 
role of $C d \times 2$ in the gut, similar to $N k \times 3.1$ in the prostate. ${ }^{3}$ In the later case, haploinsufficiency produces spontaneous hyperplastic and dysplastic lesions which themselves evolve into high grade neoplasia and carcinomas by further alteration of the tumour suppressor gene Pten. ${ }^{321}$ In the case of $C d x 2$, experimental loss of one gene copy in mice is linked to two types of lesions which are distinct as regards their type (gastric-like heteroplasias $v$ adenocarcinomas), location (pericaecal region or midgut $v$ distal colon or hindgut), and origin (spontaneous $v$ chemically induced).

The pattern of $C d x 2$ and $C d x 1$ is very different in gastric-like heteroplasias and in adenocarcinomas, confirming the distinct nature of these two types of lesions. In gastric-like heteroplasias, which represent a developmental defect linked to $C d x 2$ haploinsufficiency, total loss of expression of $C d x 2$ and $C d x I$ fits with the absence of expression of these homeobox genes in the normal stomach. The situation is different in adenocarcinomas found in the distal colon after AOM treatment as these are neoplastic lesions developing at the adult stage in normally differentiated colonic tissue. The progressive decline in $C d x 2$ in adenomatous and carcinomatous regions is consistent with reduction of expression reported in human colorectal cancers. ${ }^{14}$ Strong expression of $C d x 1$ in adenomatous regions, while expression is lost in carcinomatous regions, illustrates the different patterns of $C d \times 1$ and $C d x 2$ during colon cancer progression, and also corroborates data on the evolution of $C d x I$ in colon polyps and carcinomas in human (unpublished data).

Tumours induced by AOM in hypersensitive $C d \times 2^{+/-}$mice have similar histopathological and molecular features to those arising in wild-type animals after a longer delay. They recapitulate the adenoma-to-carcinoma sequence, have invasive properties, are localised in the distal colon in common with the majority of human colorectal cancers, and exhibit a reduction in $C d x 2$ expression with tumour progression unaccompanied by genomic alteration of the wild-type $C d x 2$ allele. Based on the fact that $C d x 2$ is downregulated by oncogenic pathways in human colon cancer cells, ${ }^{16}{ }^{17}$ we therefore propose a model in which (i) the mutagen initiates tumorigenesis by activating pro-oncogenic pathways, (ii) among other effects, these activated pathways downregulate the $C d x 2$ gene, and (iii) reduced expression of $C d \times 2$ facilitates tumour progression. It seems likely that alteration of the salvage apoptotic pathway plays a part in this cascade, possibly together with changes in cell proliferation and cell contacts. ${ }^{22-24}$ Indeed, the present study indicates that $C d \times 2^{+/-}$ mice have a diminished capacity for apoptosis, illustrated by the low activation of caspase-3 after $\gamma$ irradiation. This is consistent with the fact that $C d \times 2$ overexpression in combination with $C d x I$ in human colon cancer cells leads to reduced malignancy associated with higher sensitivity to apoptosis. $^{22}$ The preferential development of adenocarcinomas in the distal colon after AOM treatment may be related to the fact that $C d \times 2$ expression decreases towards the distal end of the colon compared with the proximal colon, perhaps reaching a threshold below which the tumour suppressor function of the gene fails to operate.

In summary, the $C d \times 2$ homeobox gene has multiple roles in the gut. During development it has a homeotic function and is an essential component of the gene complex required for midgut morphogenesis. ${ }^{6}{ }^{10-13}$ The present data suggest that it exerts a homeostatic function in adults, whose impairment facilitates tumour progression in the distal colon. In human colorectal cancers, as here in AOM treated $C d x 2^{+-}$mice, $C d x 2$ expression decreases in relation to tumour grade, while the gene is infrequently lost or mutated. ${ }^{18}{ }^{19}$ Hence the tumour suppressor $C d x 2$ may be a putative target for anti-colon cancer therapy, with the aim of restoring its expression to slow down or prevent malignant progression.

\section{NOTE ADDED IN PROOF}

The pattern of $c d x l$ in human colon cancer is described by Domon-Dell et al (Domon-Dell C, Schneider A, Moucadel E, et al. The Cdxl homeobox gene during human colon cancer progression. Oncogene 2003 (in press)).

\section{ACKNOWLEDGEMENTS}

We thank J-F Launay for help in preparing the anti-Cdxl antibody. This work was supported by INSERM and the Ministère de la Recherche (ACI-172). CB was a recipient of a fellowship by the Ministère de l'Education et de la Recherche Scientifique et Technologique. CD-D was supported by the Fondation de la Recherche Médicale.

\section{Authors' affiliations}

C Bonhomme*, I Duluc*, E Martin, M Kedinger, J-N Freund, C DomonDell, Inserm, Unit 381, 3 Ave Molière, 67200 Strasbourg, France K Chawengsaksophak, Howard Florey Institute of Experimental Physiology and Medicine, University of Melbourne, Parkville, Victoria 3052, Australia

M-P Chenard, Centre Hospitalier Universitaire de StrasbourgHautepierre, 67200 Strasbourg, France

F Beck, Biochemistry Department, University of Leicester, University Rd, Leicester LE1 7RH, UK

${ }^{*} \mathrm{C}$ Bonhomme and I Duluc contributed equally to this work.

\section{REFERENCES}

1 Cillo C, Cantile M, Faiella A, et al. Homeobox genes in normal and malignant cells. J. Cell Physiol 2001;188:161-9.

2 Maulbecker CC, Gruss P. The oncogenic potential of deregulated homeobox genes. Cell Growth Differ 1993;4:431-41.

3 Bhatia-Gaur R, Donjacour AA, Sciavolino P, et al. Roles for Nkx3.1 in prostate development and cancer. Genes Dev 1999;13:966-77.

4 Chung DC. The genetic basis of colorectal cancer: insights into critical pathways of tumorigenesis. Gastroenterology 2000;1 19:854-65.

5 Kinzler KW, Vogelstein B. Lessons from hereditary colorectal cancer. Cell 1996;87:159-70.

6 Chawengsaksophak K, James R, Hammond VE, et al. Homeosis and intestinal tumours in Cdx2 mutant mice. Nature 1997;385:84-7.

7 James R, Erler T, Kazenwadel J. Structure of the murine homeobox gene cdx2. Expression in embryonic and adult intestinal epithelium. J Biol Chem 1994; 269: 15229-37.

8 Beck F, Erler T, Russell A, et al. Expression of Cdx-2 in the mouse embryo and placenta: possible role in patterning of the extra-embryonic membranes. Dev Dyn 1995;204:219-27.

9 Silberg DG, Swain GP, Suh ER, et al. Cdx1 and Cdx2 expression during intestinal development. Gastroenterology 2000;1 19:961-71.

10 Beck F, Chawengsaksophak K, Waring P, et al. Reprogramming of intestinal differentiation and intercalary regeneration in cdx2 mutant mice. Proc Natl Acad Sci U S A 1999;96:7318-23.

11 Tamai Y, Kakajima R, Ishikawa T, et al. Colonic hamartoma development by anomalous duplication in $\mathrm{Cd} \times 2$ knockout mice. Cancer Res 1999:59:2965-70.

12 Mutoh H, Hakamata Y, Sato K, et al. Conversion of gastric mucosa to intestinal metaplasia in Cdx2-expressing transgenic mice. Biochem Biophys Res Commun 2002;294:470-9.

13 Silberg DG, Sullivan J, Kang E, et al. Cdx2 ectopic expression induces gastric intestinal metaplasia in transgenic mice. Gastroenterology 2002; 122:689-96

14 Ee HC, ErlerT, Bhathal PS, et al. Cdx-2 homeodomain protein expression in human and rat colorectal adenoma and carcinoma. Am J Pathol 1995; 147:586-92.

15 Hinoi T, Tani M, Lucas PC, et al. Loss of CDX2 expression and microsatellite instability are prominent features of large cell minimally differentiated carcinomas of the colon. Am J Pathol 2001;159:2239-48.

16 Lorentz O, Cadoret A, Duluc I, et al. Downregulation of the colon tumoursuppressor homeobox gene $\mathrm{Cdx}-2$ by oncogenic ras. Oncogene 1999; 18:87-92.

17 Kim S, Domon-Dell C, Wang Q, et al. PTEN and TNF-alpha regulation of the intestinal-specific Cdx-2 homeobox gene through a PI3K, PKB/Akt, and NFkappaB-dependent pathway. Gastroenterology 2002;123:1163-78.

18 Yagi OK, Akiyama Y, Yuasa Y. Genomic structure and alterations of homeobox gene CDX2 in colorectal carcinomas. Br J Cancer 1999:79:440-4.

19 Sivagnanasundaram S, Islam I, Talbot I, et al. The homeobox gene CDX2 in colorectal carcinoma: a genetic analysis. Br J Cancer 2001;84:218-25.

20 Marshman E, Ottewell PD, Potten CS, et al. Caspase activation during spontaneous and radiation-induced apoptosis in the murine intestine. J Pathol 2001; 195:285-92. 
21 Kim MJ Cardiff RD, Desai N, et al. Cooperativity of Nkx3.1 and Pten loss of function in a mouse model of prostate carcinogenesis. Proc Natl Acad Sci U S A 2002;99:2884-9.

22 Mallo GV, Soubeyran P, Lissitzky JC, et al. Expression of the Cdx1 and Cdx2 homeotic genes leads to reduced malignancy in colon cancer-derived cells. J Biol Chem 1998;273:14030-6.
23 Suh E, Traber PG. An intestine-specific homeobox gene regulates proliferation and differentiation. Mol Cell Biol 1996;16:619-25.

24 Lorentz O, Duluc I, DeArcangelis A, et al. Key role of the $\mathrm{Cdx} 2$ homeobox gene in extracellular matrix-mediated intestinal cell differentiation. J Cell Biol 1997; 139:1553-65.

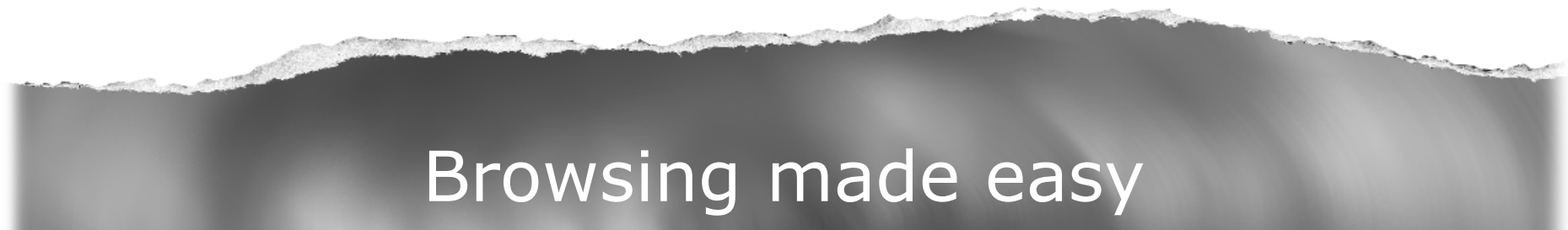

\section{Collections}

With a single click Collections allows you to find all articles that have been published in your chosen subject. Select from over 200 clinical and non-clinical topic collections and/or cross search other specialist journals, the BMJ and Cochrane Reviews

\section{www.gutjnl.com}

